\title{
Los títeres de Rosete Aranda y su restaurador: Sergio A. Montero
}

\author{
Ana Garduño Ortega
}

\author{
Una marioneta \\ se convierte en un simple muñeco \\ cuando se instala en una vitrina. \\ Sergio A. Montero Alarcón (restaurador)
}

\section{Los títeres}

os orígenes de la Compañía Rosete Aranda se ubican en Huamantla, Tlaxcala: en 1835, se fundó la Empresa Nacional de Autómatas, con cuatro miembros de la familia Aranda, quienes confeccionaron la primera generación de títeres; se trataba de alumnos destacados de un titiritero inmigrado de Italia de apellido Aquino. En una siguiente etapa de la empresa, ésta adquirió el nombre con el que ha alcanzado trascendencia, nacido de la unión matrimonial de una de las fundadoras, María de la Luz Aranda, con Antonio Rosete. Sus descendientes trasladaron su arte a la ciudad de México durante las últimas décadas de ese siglo XIX. Alternando los espectáculos en su sede citadina con sus giras nacionales e interamericanas, lograron un prestigio y distinción que a lo largo del siglo XX se convirtió en leyenda, urbana y huamantleca.

Buena parte de su fortuna crítica recayó tanto en la complejidad técnica de las representaciones como en la destreza de los entrenados titiriteros. Para las primeras décadas del siglo Xx, el acervo se componía de cerca de 3000 piezas y su repertorio incluía alrededor de 100 narrativas, algunas de las cuales implicaban un considerable número de muñecos en escena. Hacia 1941, la compañía desapareció formalmente, aunque la colección hacía años que se había segmentado: un porcentaje significativo fue adquirido por un recinto museístico estadounidense, con lo que se garantizó su preservación; otra sección vivió procesos diversos de comercialización, hasta que en los años ochenta el INBA adquirió un conjunto representativo de muñecos, otrora propiedad de la familia Espinal.

A pesar de que, con el cierre de la emblemática empresa, concluyó una época de oro del títere, estaban sentadas las bases para la continuidad de un espectácu lo que ha vivido diversos revivals, alternados con fases de decadencia. Dados los altibajos naturales en el gusto popular de una tradición que con dificultad ha mantenido la vigencia de su lenguaje, y que hoy se la presenta reducida a divertimento infantil, su proceso de institucionalización fue lento, razón por la que no fue sino hasta 1991 cuando se fundó el Museo Nacional del Títere Rosete Aranda (MUNATI), en la ciudad de Huamantla. Más aún, en los últimos tiempos se ha consumado la oficialización del arte escénico con marionetas, a través del Instituto Tlaxcalteca de Cultura (ITC) y del ya mencionado MUNATI, que otorgan 
anualmente el Premio Rosete Aranda; además, el Festival Internacional del Títere cuenta con amplia trayectoria, entre algunas otras iniciativas similares.

\section{El restaurador}

Sergio Arturo Montero es uno de los principales fundadores de la restauración como disciplina profesional en México y, en consecuencia, ha fungido como trascendental formador de los restauradores educados en el INAH durante cerca de 50 años. En junio de 2009, el profesor Montero finalizó la intervención del significativo lote de 317 títeres, todos ellos amparados bajo el prestigiado patronímico de Compañía Rosete Aranda y adscritos al acervo del INBA.

Como todo conservador profesional sabe, al profesor Montero se le ubica primordialmente en el territorio de la conservación-restauración de pintura mural y escultura pública, sobre todo monumental. Varios de sus proyectos hoy son paradigmáticos, tanto por los avances que han representado para el desarrollo nacional de la restauración como por su evidente capacidad de decisión y su vocación por la experimentación, cualidades indispensables en una época en que la disciplina profesional de la restauración estaba en cimentación.

Son emblemáticas sus restauraciones de la estela 1 de la Gran Plaza de Bonampak, en donde se muestra al gobernante Chaan Muan II en todo su esplendor iconográfico; de la escultura en adobe crudo de El Zapotal, descubierta en 1978, que dio origen al museo de sitio, dada la inconveniencia de su traslado por la frágil naturaleza de la inusual pieza que personifica a Mictlantecuhtli, deidad relacionada con la muerte y el inframundo. De sus trabajos murales, sólo quiero mencionar dos: el enorme Poliforum Cultural Siqueiros, construido a inicios de los años setenta del siglo pasado y que presenta problemas de conservación prácticamente desde el inicio, por los errores técnicos que se cometieron en su confección, y su reiterada intervención en los murales decimonónicos de la casa conocida como La Moreña, en La Barca, Jalisco, en 1972 y, en una segunda fase, a partir de 2007.

Dentro de la productiva y reconocida trayectoria del profesor Montero, poco ha trascendido su involvement en el universo de las marionetas, en tanto antiguo hacedor de muñecos, escenografías y teatrinos portátiles; creador y ejecutante de espectáculos desde su agrupación familiar de títeres, Ikerin; eficaz directivo de uno de los más importantes organismos gremiales nacionales, el Centro Mexicano de la Unión Internacional de la Marioneta (UNIMA), y, por supuesto, cuidadoso restaurador de títeres, de hecho el que mayor experiencia ha acumulado en este rubro.

\section{El proyecto}

Mediante una colaboración pactada del INAH-INBA, entre 2007 y 2009 se realizó la restauración del lote arriba citado, caracterizado por dos tipos de manufacturas: una más

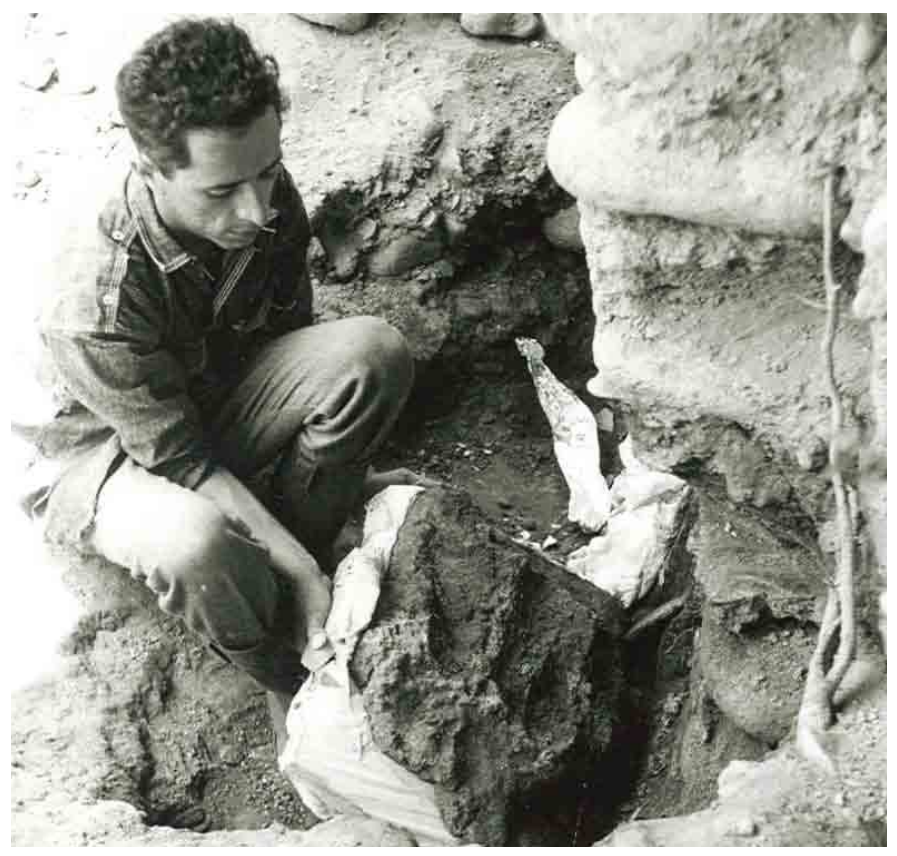

FIGURA 1. Sergio Arturo Montero realizando un proceso de rescate arqueológico en Las Higueras, Veracruz, en 1967. (Cortesía de Sergio Arturo Montero Alarcón.)

antigua y burda, atribuida a la familia Rosete Aranda, y otra de mayor refinamiento, supuestamente confeccionada por la familia Espinal. Se atendieron con base en las cualidades estéticas e históricas de las piezas y con el objetivo de devolver la posibilidad de que las marionetas salgan a escena. Con la contundencia que lo caracteriza, Montero declaró a la prensa: "Tengo la certeza de que los títeres, metidos en una vitrina, dejan de ser títeres. Se les tiene que devolver su entorno, recuperar su funcionamiento, si no, no son títeres" (Cid de León 2009).

Con ello, el experimentado profesor señala al punto neurálgico de la cuestión: si se restauran títeres con la pretensión de reconstituir la funcionalidad de un objeto, su operatividad queda seriamente restringida por su clasificación de bien cultural antiguo, ya que las piezas fueron facturadas de 1835 a las primeras décadas del siglo XX. Más aún, la declaratoria que recibieron en los años noventa de Patrimonio de la Nación, si bien las protege de una posible destrucción, no promueve su eventual retorno a escena, sino, más bien, su exclusión definitiva, haciendo que su confinamiento en bodegas no sea una fase de transición entre una actuación y otra, sino su destino final. En otros casos, los ejemplares mejor cotizados, por su rareza o belleza, se ubicarán en aparadores de exposiciones diversas, temporales o permanentes.

Todo indica que el futuro de esta colección es el letargo y la inactividad. En este sentido, cabe preguntarse: ¿cómo hacer para que una declaratoria de monumento artístico-histórico no petrifique un instrumento tan heterodoxo como el títere? Y es que, a diferencia de un bien inmueble, sea una pirámide o una casa-habitación donde hace mu- 
cho nació alguno de esos héroes que nos dieron patria y libertad, o de un bien mueble, como la loza china de la Compañía de Indias o un óleo costumbrista decimonónico, el títere es un artefacto que, más allá de sus valores estéticos-históricos, se caracteriza por su valor de uso, por su necesaria interactuación con el titiritero para activar su potencial comunicacional, lúdico.

Cierto es que restaurar no es equivalente a reutilizar, a revitalizar; también lo es que los museos, al parecer de manera inevitable, fetichizan y trastocan la misión original de aquello que exhiben. Es por ello que colocar en vitrinas del espacio museal una ambientación con marionetas a la que sólo hace falta el visitante curioso, y ocioso, que accione un botón para su movilidad, a medio camino entre las máquinas y los autómatas, tampoco parece ser una opción que convenza al profesor Montero, ya que no restituye la plena operatividad de los títeres ni pone en acción sus cualidades narrativas.

Estas contradicciones hacen retornar a la mesa de las discusiones -alrededor de la cual nos reunimos virtualmente historiadores y conservadores- una añeja problemática: si bien una de las necesarias finalidades al intervenir un objeto es la recuperación de su función original, al tratarse de piezas con alta significancia documental el mayor logro será conservar sus valores históricos. No obstante, en aqueIlos objetos fabricados para la performance, la actuación, se acentuará el drama de su no funcionalidad, independientemente de que se los coloque en un almacén iluminado y de visibilidad garantizada (museo) o en una bodega con necesarias restricciones en iluminación, temperatura y humedad, además de inaccesible para público alguno.

\section{Las intervenciones y sus fundamentos}

Cabe destacar que Montero ha materializado cuatro intervenciones profesionales en grupos diversos de piezas a lo largo de 25 años, todas ellas en títeres registrados bajo el genérico de Compañía Rosete Aranda, sin duda las que mayor fortuna crítica poseen dentro de las fronteras nacionales. En el contexto de la ceremonia de entrega de esta última, se realizó un breve diálogo para conocer los pormenores de la intervención al acervo arriba citado.

¿En qué han consistido sus proyectos de restauración de títeres?

Sergio A. Montero (SAM): El primero tuvo lugar en 1983 y correspondió a un lote del Centro de Teatro Infantil del INBA. EI actor y productor Enrique Alonso, en su afán de evocar a los Rosete Aranda, montó tres espectáculos con esos títeres a los que llamó Titiriglobo. El segundo ocurrió en 1989-1990, y se trató de un conjunto perteneciente al conocido pintor y coleccionista Rafael Coronel, resguardado en el museo que lleva su nombre en la ciudad de Zacatecas. En los dos siguientes, en 1995 y este último, de 2007-2009, se intervinieron piezas que forman parte del acervo del INBA.

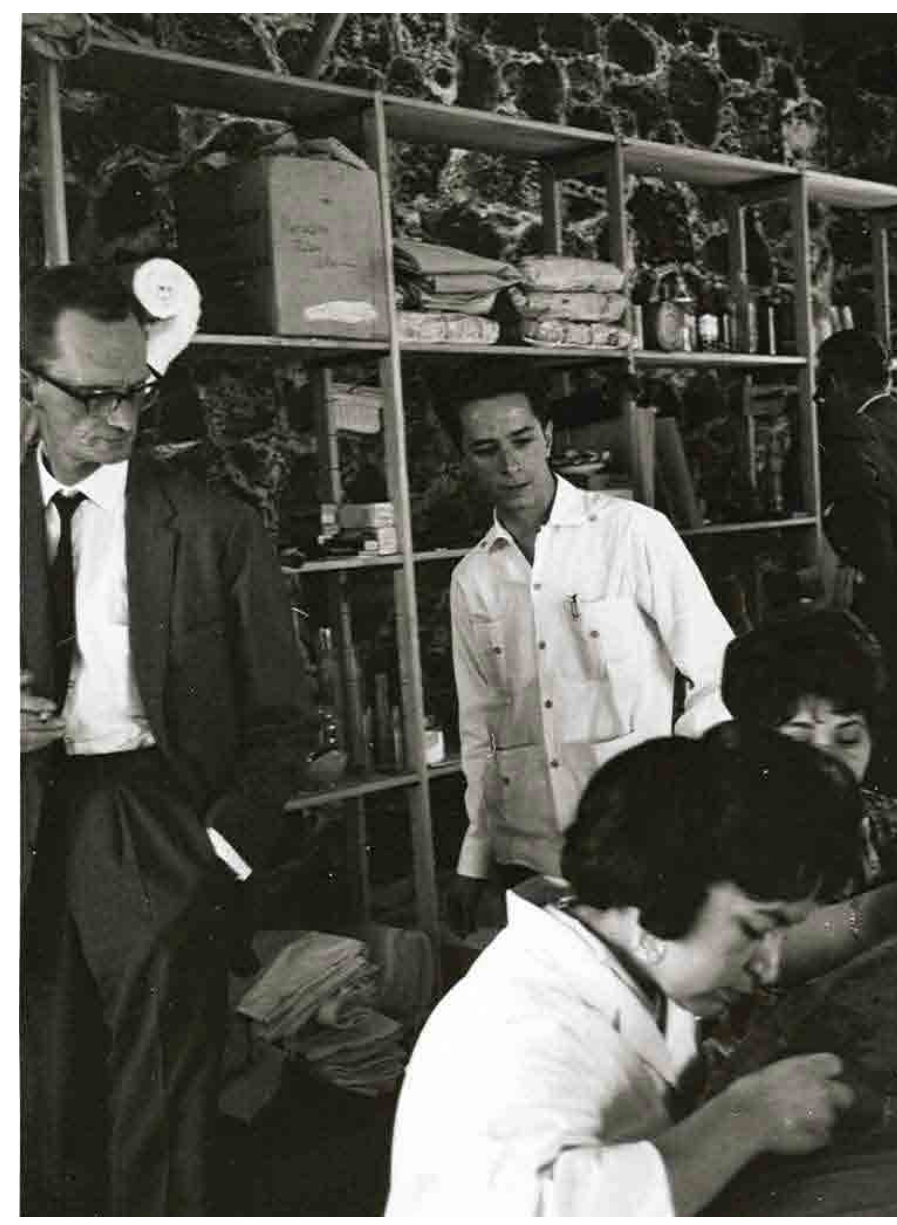

FIGURA 2. Paul Coremans y Sergio A. Montero a principios de la década de 1960 en las instalaciones del Centro Churubusco, antecedente de la Escuela Nacional de Conservación, Restauración y Museografía (ENCRyMINAH). (Cortesía de Sergio Arturo Montero.)

¿Ha restaurado objetos que hayan sido intervenidos previamente y en los que se hubiera dañado el mecanismo de movimiento del títere?

SAM: En realidad sólo he trabajado con los títeres de la Compañía Rosete Aranda. La mayoría de ellos fue arreglada por los propios titiriteros, puesto que el uso constante produce deterioros. A pesar de que esas reparaciones desencadenaron alteraciones estéticas en los acabados, no atrofiaron su mecanismo, pues debían continuar utilizándose en escena. Los daños en la estructura se produjeron por la falta de medidas de conservación, después de la disolución de la citada compañía, en 1941.

¿Cuáles eran los principales estropicios en los objetos?

SAM: Salvo algunos detalles específicos de algunas de las piezas, todas ellas presentaban los mismos deterioros: vestuario muy sucio y maltratado por el uso, ataque de insectos, roedores y moho; faltantes de algunos elementos, en especial extremidades: brazos, manos, piernas, pies; tronco atacado por carcoma, con agujeros de tachuelas o clavos; 
oxidación de éstos, que provocó destrucción de fibras textiles y leñosas. Casi todas las cabezas revelaron repintes generales de mala factura y en varios estratos, que alteraban y ocultaban la policromía original, de excelente calidad, aunque con algunos desgastes.

¿En qué consistieron los tratamientos realizados?

SAM: Diagnóstico del estado de conservación en cada pieza, retiro del vestuario para su lavado y desmanchado, reparación de rasgaduras y roturas, reposición de elementos faltantes $y$, en caso de destrucción irreparable, sustitución del vestuario completo o de forma parcial, con base en su diseño original. Asimismo, reposición de elementos estructurales faltantes, tallándolos en el mismo tipo de madera original, para recuperar el mecanismo; eliminación de repintes en las cabezas y reintegración cromática en las lagunas; consolidación y/o cambio de los sistemas de articulaciones. Todos estos procesos tuvieron la misma importancia para lograr la restauración integral, en función de recuperar sus

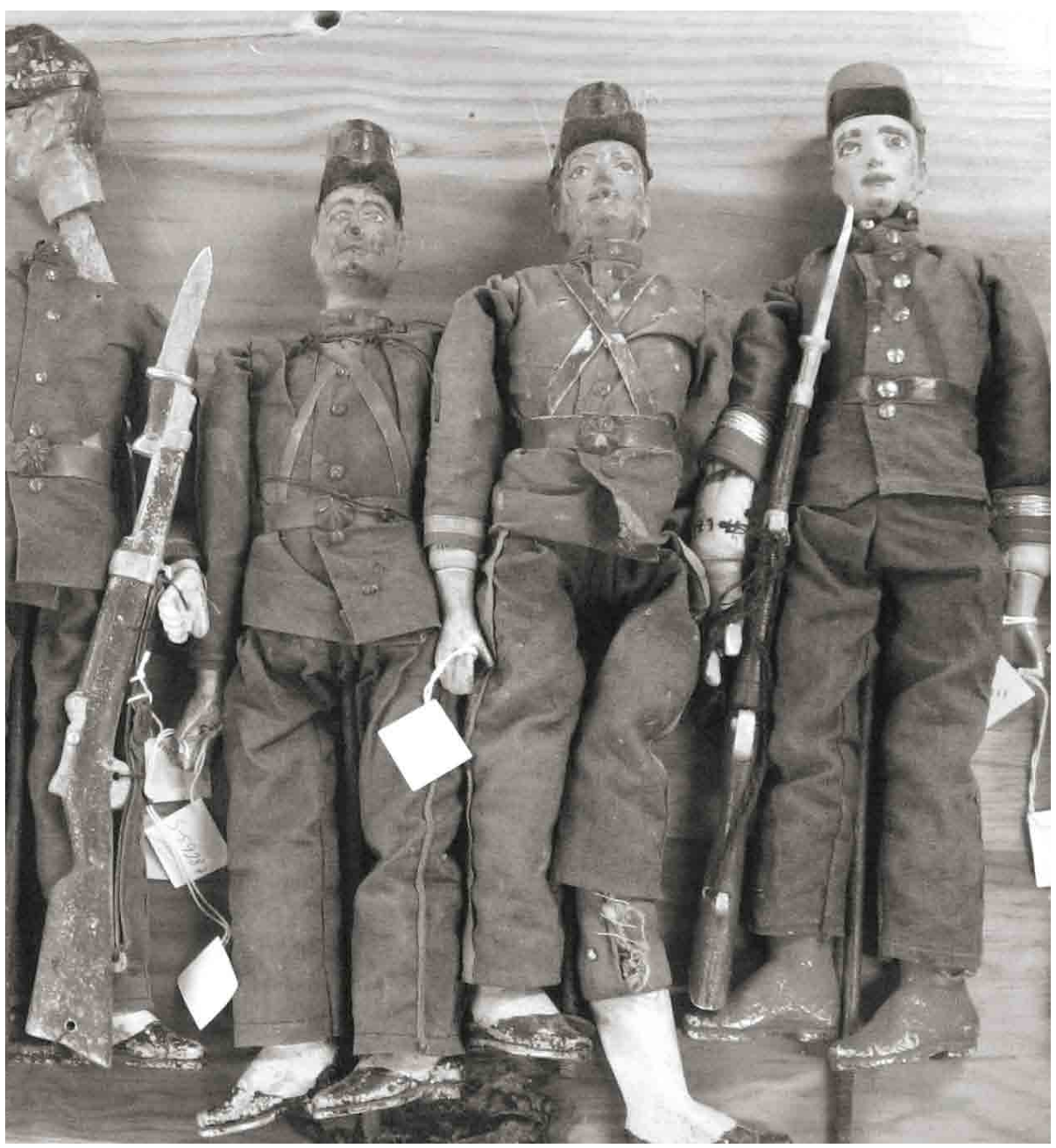
movimientos para que, eventualmente, se presenten en escena. No se encordaron por falta de recursos económicos.

¿Considera una desventaja haber intervenido diferentes lotes en distintas épocas?

SAM: No hay desventajas. Lo importante es que en cada intervención se ha logrado rescatar parte de este patrimonio cultural.

¿De qué manera aspectos funcionales y de representación teatral han sido determinantes en la restauración de títeres, en relación con aspectos estéticos, de originalidad o historicidad?

SAM: Todos estos aspectos en su conjunto son determinantes. Ninguno tiene mayor importancia sobre los otros, y esto se refiere a la restauración de cualquier bien cultural.

En un artículo de 1995 en la revista Imprimatura (Montero 1995:6), usted aseveró que la restauración de títeres debe abordarse de manera multidisciplinaria, haciendo converger en un mismo proyecto a restauradores, titiriteros, historiadores y autoridades de teatro. ¿Considera haber logrado la tan buscada interdisciplina en este último ejercicio?

FIGURA 3. Uno de los lotes de la Colección Rosete Aranda antes de su restauración en 2008. (Fotografía tomada por Rest. Claudia Malváez López, cortesía de Lic. Verónica Fernández Espinosa, Proyecto de Restauración de Títeres 2008, Archivo de la ENCRyM-INAH.)

SAM: No se logró cabalmente a causa de la carencia de recursos económicos. Se sustituyó parcialmente con base en mi conocimiento de los títeres, lecturas sobre su historia, y se aprovechó en algo la investigación que el Centro Nacional de Investigación, Documentación e Información Teatral Rodolfo Usigli (CITRU-INBA) realiza actualmente sobre la Compañía Rosete Aranda.

¿Cuáles han sido las diferencias primordiales entre su restauración de títeres y las ejecutadas por otros?

SAM: La principal divergencia es que otras intervenciones no las realizaron restauradores profesionales y, por lo tanto, no se ajustan a los principios y ética de la restauración, respondiendo sólo a intereses particulares.

¿Considera que un egresado de la Licenciatura en Restauración de la ENCRYM, con conocimientos de restauración en materiales tales como pintura en diversos soportes, escultura policromada, textiles, papel, etc., está capacitado para 


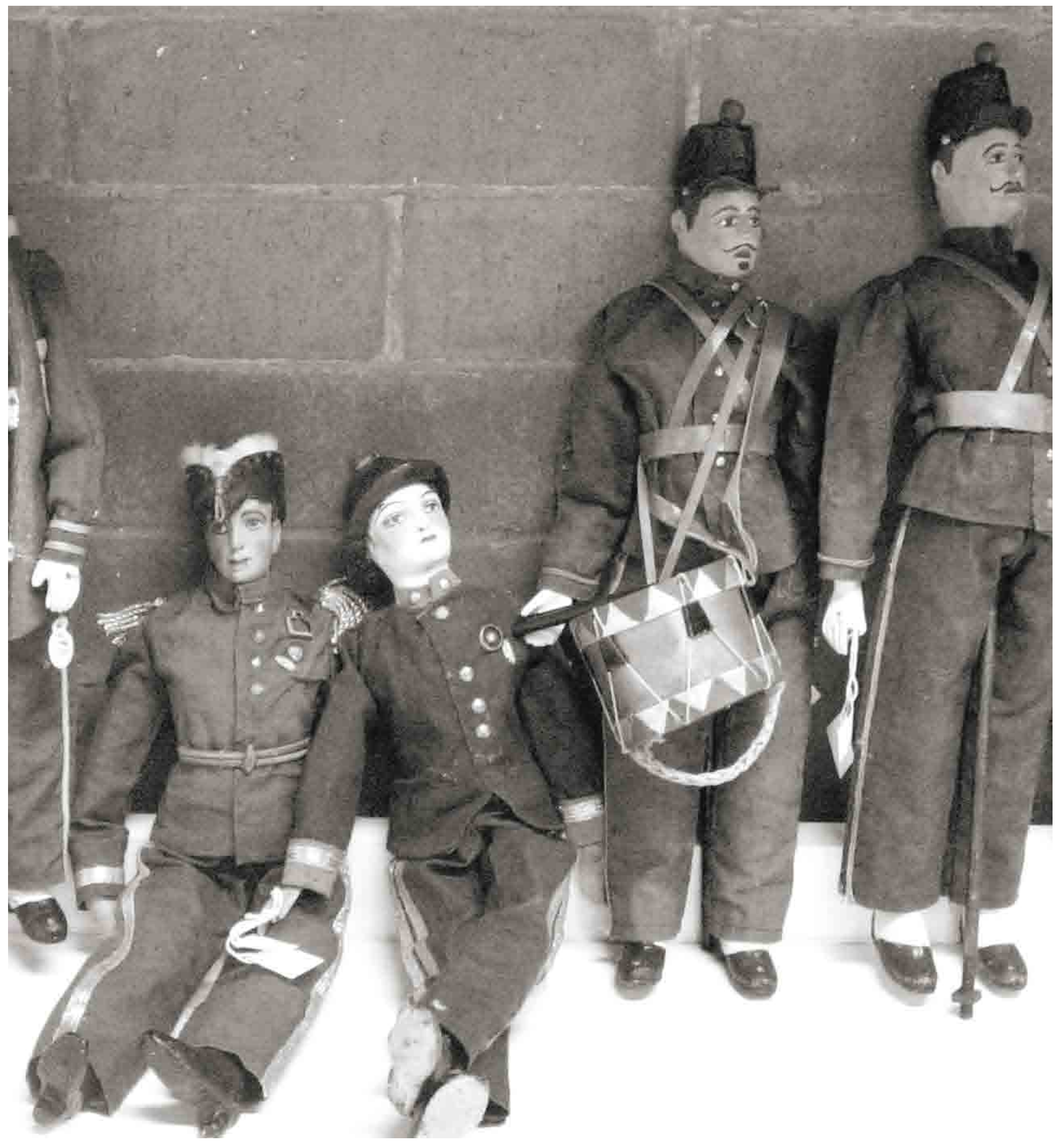

restaurar de la mejor manera posible un espécimen tan particular como un títere?

SAM: De acuerdo con el Plan de Estudios de la ENCRyM, sus egresados están habilitados para intervenir todo tipo de bienes culturales, tanto desde el punto de vista material, como de sus valores estéticos, históricos y funcionales, es decir, su contexto. Si estos últimos no son conocidos por
FIGURA 4. Lote de títeres de la Colección Rosete Aranda después de su restauración en 2008, bajo la coordinación de Sergio Arturo Montero. (Fotografía tomada por Rest. Andrea Figueroa Elizalde, cortesía de Rest. Lourdes González Jiménez, Proyecto de Restauración de Títeres 2008, Archivo ENCRYM-INAH.)

el restaurador, para eso los prepara la escuela con bases sólidas en investigación, requisito indispensable para trazar y ejecutar cualquier proyecto de restauración. 
¿Formó parte del equipo que en 1991 creó el Museo Nacional del Títere en Huamantla, Tlaxcala?

SAM: No participé en la creación del museo, pero a partir de su inauguración y hasta 2004, como socio fundador y presidente en dos ocasiones de la UNIMA, colaboré constantemente con apoyos y asesorías, tanto para el propio museo como para el Festival Internacional de Títeres de Tlaxcala que el citado recinto organiza anualmente.

¿Es usted el único especialista en la materia? ¿Con su retiro, se extingue una tradición en la restauración de títeres en México?

SAM: Las especialidades en la conservación -y creo que esto puede aplicarse a cualquier profesión-se dan por afinidades, gustos o necesidades de la demanda. Debido a que además de restaurador soy titiritero, de manera natural me enfrenté al problema de la restauración de marionetas, pero, por la magnitud del último proyecto, fue necesario conformar un equipo de conservadores que aplicaron sus conocimientos y experiencia, adquiriendo el gusto y el amor por los títeres, realizando un magnífico trabajo, por lo que auguro una nueva generación de restauradores con esta especialidad.
Por otra parte, mi retiro es en tanto empleado del INAH, mas no de la profesión.

Este último comentario hace referencia a que el cierre de este proyecto proporciona no sólo una excelente oportunidad para acercarse a tan significativa como desconocida faceta del maestro Montero, sino que también preludia su despedida oficial del INAH, en tanto coordinador de proyectos especiales de restauración, y en su papel de reconocido docente de la ENCRyM, mediante una jubilación que no implica -según su propia aclaración- un retiro absoluto de la profesión que con enjundia y pasión ha ejercido durante cerca de medio siglo.

\section{Referencias}

Cid de León, Óscar

2009 "Reviven marionetas de Rosete Aranda", Reforma, Sección Cultura, 24 de junio, documento electrónico disponible en www.reforma.com/cultura/articulo/505/1008852/

Montero Alarcón, Sergio A.

1995 "La restauración de los títeres de Rosete Aranda", Imprimatura. Revista de Restauración 11: 3-6.

\section{Resumen}

Mediante una colaboración pactada del Instituto Nacional de Antropología e Historia (INAH) y el Instituto Nacional de Bellas Artes (INBA), entre 2007 y 2009 se realizó la restauración de un lote de títeres como parte de un proyecto coordinado por el acreditado profesor Sergio A. Montero Alarcón, docente de la Escuela Nacional de Conservación, Restauración y Museografía (ENCRyM-INAH). Se trata de dos tipos de marionetas: uno de manufactura antigua y burda, atribuida a la familia Rosete Aranda, y otro de mayor refinamiento, supuestamente confeccionado por la familia Espinal. En esta contribución, Ana Garduño Ortega dialogó con el maestro Montero sobre el proceso de intervención de este lote de títeres, enfatizando no sólo la importancia de mantener un balance sobre los valores estéticos, históricos y funcionales de los muñecos, sino también el de restablecer su potencial regreso a escena.

\section{Palabras clave}

Restauración, títeres, Sergio A. Montero Alarcón, Rosete Aranda, Carlos Espinal.

\section{Abstract}

Through an established collaboration between the Instituto Nacional de Antropología e Historia (INAH) and the Instituto Nacional de Bellas Artes (INBA), between 2007 and 2009 a large group of string-puppets was restored by a project directed by the Professor Sergio A. Montero Alarcón, teacher of the Escuela Nacional de Conservación, Restauración y Museografía (ENCRyM-INAH). The group was composed by two kinds of string-puppets: one of them was of an old and rough facture attributed to the Rosete Aranda family, while the other of refined craftship was supposedly produced by the Espinal family. In this article, Ana Garduño Ortega talks with Professor Montero about the intervention process of the string puppets, emphasizing not only on the importance of maintaining a balance between its aesthetic, historical, and functional values, but also on restoring its performance potential.

\section{Keywords}

Restoration, String puppets, Sergio A. Montero Alarcón, Rosete Aranda, Carlos Espinal. 